\title{
La perspectiva del recuerdo: Proust desde Ortega ${ }^{1}$
}

\section{(The perspective of remembrance: Proust through Ortega)}

\author{
ESMERALDA BALAGUER GARCÍA \\ esmeralda.balaguer@latorredelvirrey.es \\ Universidad Complutense de Madrid
}

Fecha de recepción: 19 de septiembre de 2019

Fecha de aceptación: 23 de octubre de 2019

Resumen: El artículo pretende dar cuenta del carácter del recuerdo en la novela En busca del tiempo perdido de Marcel Proust, teniendo en cuenta las reflexiones que Ortega escribe sobre Proust en 1923 y sobre la novela en 1925. La primera parte del escrito abordará las reflexiones de Ortega sobre la obra de Proust como ejemplo de la novela moderna. La segunda parte tratará de clarificar por qué el recuerdo se gesta como una estructura para recuperar el pasado y qué papel juegan el olvido y la memoria en el mecanismo del recordar.

Palabras clave: Proust. Ortega. Recuerdo. Memoria. Olvido.

Abstract: The article seeks to show the characteriology of remembrance in the Marcel Proust novel $\dot{A}$ la recherche du temps perdu, taking into account the considerations that Ortega wrote about Proust in 1923 and about the novel in 1925. The first part of the paper explain why the Proust novel is an example of modern novel for Ortega. The second part of the article try to clarify why the remembrance is a structure to recover the past and what role play the forget and the memory.

Keywords: Proust. Ortega. Remembrance. Memory. Forget.

Como Harold Bloom sostuvo, Marcel Proust fue el gran novelista de su tiempo, al igual que Freud fue el gran moralista (2004: 1). Ortega, que siempre tuvo un buen olfato para detectar grandes pensadores, encontró en Proust, con

\footnotetext{
${ }^{1}$ Este trabajo se enmarca en el siguiente proyecto de investigación: Redes intelectuales y políticas: la tradición liberal en torno a José Ortega y Gasset (FFI2016-76891-C2-2-P)
} 
tan solo tres de los primeros tomos de $\dot{A}$ la recherche $d u$ temps perd $u^{2}$ publicados, a un inventor, o, dicho de otro modo, a alguien que había sabido redescubrir un nuevo trato con el tiempo y una nueva forma de instalarse en el espacio. Ortega y todos los lectores de Proust podemos encontrar en su novela un poco de tiempo en su estado más puro.

En las siguientes páginas me propongo abordar, desde la óptica que ofrece la reflexión orteguiana, una lectura de Proust cercana al propio sentido del recuerdo y a los mecanismos que intervienen en su gestación. La relación de la filosofía con la literatura es tan antigua como el pensamiento. Tan solo de la literatura podemos extraer las enseñanzas que nos faltan para vivir. Es por ello por lo que la filosofía debe apoyarse en la literatura para construir una narración más cercana a la realidad. Siguiendo a Américo Castro, la literatura es crucial para esclarecer aspectos de la historia y para apoderarnos de una imagen de la historia que sí cuenta la vivencia de los que perdieron o fracasaron.

\section{Marcel Proust: ejemplo de novela moderna}

La recepción de Proust en España la propició Ortega, que conocía muy bien el panorama de la literatura francesa desde temprana edad. Los primeros tres tomos de los siete totales que componen esta gigantesca obra fueron editados y traducido por el escritor Pedro Salinas a instancias de Ortega. Frente a la dura crítica de la novela como un género en decadencia que Ortega vertió en 1925 en Ideas sobre la novela, deliberadamente salvó a Proust en esta discusión. Ortega ya había exaltado a Proust en un ensayo anterior que escribió para la revista francesa La Nouvelle Revue Française en 1923 con motivo de un homenaje a Proust tras su muerte. Este homenaje, que se publicó en enero de ese mismo año, apenas dos meses después del fallecimiento del novelista, se compuso de 65 aportaciones tanto de pensadores y escritores franceses como extranjeros. Entre ellos destacan la poetisa Anna de Noailles, Robert Proust, el hermano menor de Marcel Proust, el afamado editor Gaston Gallimard, el poeta y cineasta Jean Cocteau, el poeta Paul Valéry, el escritor y crítico literario Charles du Bos, el filólogo y crítico literario Ernst Robert Curtius, el crítico literario Benjamín Crémieux y el propio Ortega. Con Crémieux Ortega tuvo una polémica a propósito de su interpretación de Proust. La diferencia fundamental entre ambas críticas estaba en que Ortega interpretaba la obra de Proust como una práctica de no-intervencionismo, esto es, como un ejercicio de lo

\footnotetext{
${ }^{2}$ La edición utilizada para el análisis de esta obra de Proust es: Proust, Marcel, En busca del tiempo perdido, trad. de Pedro Salinas y Consuelo Berges, 7 vol. Madrid: Alianza, 2011-2018. Utilizo esta edición precisamente porque los tres primeros volúmenes fueron traducidos por Pedro Salinas a instancias de Ortega.
} 
involuntario de la memoria. En cambio, Crémieux sostenía que la novela era un acto deliberado de construcción y de dinamismo. En agosto de 1924 se publicaba en Revista de Occidente un artículo de Crémieux precedido por una breve nota de Ortega, que presentaba a Crémieux como "uno de los escritores franceses más capaces de pensar" (2004-2010, III: 709) y cuyo ensayo sobre Proust era lo mejor que se había compuesto, a pesar de ese desencuentro de puntos de vista que habían tenido dos años antes sobre las ideas que Ortega había sostenido con respecto a Proust en el Homenaje de la NRF. En la nota Ortega afirmaba que pronto publicaría un trabajo más completo sobre Proust — que nunca llegó a aparecer- como respuesta a las críticas y desencuentros con Crémieux. Ideas sobre la novela se presentaba como una respuesta de Ortega a Crémieux. Esta es una tesis que ha sido defendida por el investigador Herbert E. Craig.

En Ideas sobre la novela repitió indirectamente muchas de las tesis que había expuesto en este ensayo, titulado "Tiempo, distancia y forma en el arte de Proust". Para Ortega, Proust era el reflejo de la novela moderna, junto a Dostoyewsky y Stendhal y aunque llegó a sostener que "la obra de Proust es una 'novela paralítica", según H.E. Craig, Ortega utiliza "la Recherche como el ejemplo de un caso límite" para definir la novela moderna (Craig 1986: 450).

La obra de Proust cumplía muchas de las características que Ortega le atribuía a la novela moderna y que podemos encontrar diseminadas en Ideas sobre la novela. Estas características de la novela moderna eran las siguientes:

1. El carácter de morosidad y retardatario o de lentitud (tempo lento). La novela describía más que narraba, por consiguiente, quedaba anulada la trama y el interés dramático. Escribía Ortega a propósito de Proust:

En Proust la morosidad, la lentitud llega a su extremo y casi se convierte en una serie de planos estáticos, sin movimiento alguno, sin progreso ni tensión. Su lectura nos convence de que la medida de la lentitud conveniente se ha traspasado. La trama queda casi anulada y se borra el postrer resto de interés dramático. La novela queda así reducida a pura descripción inmóvil, y exagerado con exclusivismo el carácter difuso, atmosférico, sin acción concreta que es, en efecto, esencial al género (2004-2010, III: 893).

Una muestra de este carácter moroso en En busca del tiempo perdido lo encontramos, por ejemplo, en la extensa descripción del salón de la marquesa de Villeparisis — amiga de la abuela de Proust y tía de Saint-Loup, amigo de 
ESMERALDA BALAGUER GARCÍA

Proust, a quien conoce en un viaje que realiza con su abuela a Balbec - en "El mundo de Guermantes" (tomo III).

2. Hay un profundo análisis de las pasiones y los sentimientos, que en Proust se ve reflejado en las historias amorosas que mantiene a lo largo de la obra (con Gilberta de Swann, Albertina Simonet u Oriana, la duquesa de Guermantes). Todas ellas son dolorosas y celosas. Incluso la relación de Proust con su madre y con su abuela es tormentosa. Al inicio de "Por el camino de Swann" (tomo I), Proust nos cuenta con profunda insistencia cuánta angustia le generaba durante el transcurso del día la espera por el beso tan ansiado de su madre y que solo llegaba con el crepúsculo, al caer la noche y cuando su padre lo permitía. Él solo vivía para eso y esta era la fuente de sus amarguras y de sus alegrías.

\begin{abstract}
Así que ya me estaba yo prometiendo para cuando, estando todos en el comedor, empezaran a cenar ellos y sintiera yo que se acercaba la hora, sacar por anticipado de aquel beso, que habría de ser tan corto y furtivo, todo lo que yo únicamente podría sacar de él: escoger con la mirada el sitio de la mejilla que iba a besar, preparar el pensamiento para poder consagrar, gracias a ese comienzo mental del beso, el minuto entero que me concediera mi madre a sentir su cara en mis labios (2011-2018, I: 45).
\end{abstract}

3. Se concentra la trama en el tiempo y en el espacio, es decir, hay acontecimientos que solo pasan en un día y en un lugar, como la trama que se desarrolla durante el tomo VI, "La prisionera", donde todo sucede en el apartamento de Proust, pues Albertina se ha visto en la tesitura de tener que vivir irremediablemente con él.

4. El agente de las obras es el ambiente. Sostenía Ortega que "la esencia de lo novelesco — adviértase que me refiero tan sólo a la novela moderna- no está en lo que pasa, sino precisamente en lo que no es 'pasar algo', en el puro vivir, en el ser y el estar de los personajes, sobre todo en su conjunto o ambiente.” (2004-2010, III: 898). Los personajes de Proust son pasivos, nunca les pasa nada porque no tienen quehacer, viven sumergidos bajo los destinos atmosféricos, que son los que deciden verdaderamente las variaciones vitales de los personajes. Esta es una idea que Ortega sostuvo en el ensayo para la revista francesa:

En suma, Proust aporta a la literatura lo que pudiera denominarse una intención general atmosférica. Paisajes y personas, mundo interior y exterior, todo queda 
volatilizado en una aérea palpitación difusa. Yo diría que el universo de Proust está hecho para ser percibido en forma de respiración porque todo en él es ambiente. En estos volúmenes nadie hace nada ni pasa nada: todo es una pasiva sucesión de situaciones estáticas. Ni podía acontecer de otra manera, porque, para hacer algo, es menester antes ser algo determinado (2004-2011, II: 795).

Para Ortega, la obra de Proust producía una peculiar fatiga que nada tenía que ver con el aburrimiento, sino más bien con esta interpretación atmosférica de la vida humana y con la minuciosidad en la descripción de cada imagen de recuerdo. Constantemente nos sentimos detenidos en la lectura.

5. La esencia de la novela moderna, como ya he citado antes, es el puro vivir de los personajes.

6. El lugar para la descripción puede ser cualquiera, pero el ideal es la provincia, por eso el libro empieza en el imaginario pueblo francés Combray. Esto responde a la necesidad de limitar el horizonte paisajístico del lector y aislarlo de su mundo real. Solo de este modo podrá instalarse dentro de la narración.

\begin{abstract}
Hacer de cada lector un "provinciano" transitorio es, en mi entender, el gran secreto del novelista. Por eso decía antes que en vez de querer agrandar su horizonte —¿qué horizonte o mundo de novela puede ser más vasto y rico que el más modesto de los efectivos? - ha de tender a contraerlo, a confinarlo. Así y sólo así se interesará por lo que dentro de la novela pase (2004-2011, III, 899).
\end{abstract}

7. La plenitud de detalles. En el ensayo sobre Proust, Ortega sostenía que su escritura era nimia y prolija porque se acercaba más de lo acostumbrado a los objetos con el fin de describirlos. Según Ortega, Proust inventó una nueva distancia entre nosotros y las cosas. Esto se ve muy bien en la larga descripción de las facciones del rostro de Albertina que Proust hace en $A$ la sombra de las muchachas en flor (T. II).

8. La materia de la novela moderna es la psicología imaginaria. En este punto se ve reflejado como en muchas ocasiones la literatura se adelanta a la psicología. Proust, que había leído poco a Freud, usaba su imaginación y su experiencia para analizar a los personajes de su libro. Escribía Ortega: "esta posibilidad de construir fauna espiritual es, acaso, el resorte mayor que puede manejar la novela futura $[\ldots]$. No en la invención de 'acciones', sino en la 
invención de almas interesantes veo yo el mejor porvenir del género novelesco" (2004-2011, III: 907).

En muchos aspectos, Proust y Ortega se asemejan y esto me parece representativo porque ambos, en su peculiaridad, sobresalían por encima del resto. Por ejemplo, tenían una gracia única para nombrar sus libros. El título que Proust dio a cada uno de los tomos de su obra anuncia el espectáculo que va a presenciar el lector al adentrarse en el mundo proustiano. Desde Por el camino de Swann, hasta Sodoma y Gomorra, La prisionera, La fugitiva y por último El tiempo recobrado, encontramos en estos títulos las metáforas representativas de un momento vital de Proust.

Proust también estuvo atormentado por la necesidad de ser fiel a su vocación. Una vocación de escritor que despuntaba desde su infancia y que se vio, una y otra vez, aplastada por los grandes personajes que habitaban los lujosos salones de las mayores damas de la época, donde se reunía la más alta sociedad parisina. Adorno dedica el primer fragmento de Minima Moralia (1944) a Proust. Dice que aquel que se entrega al oficio de hombre de letras encuentra el verdadero obstáculo en que no se reconoce su labor con el espíritu como una ocupación, es decir, "él no es ningún 'profesional', ocupa un rango en la jerarquía de los concurrentes como diletante sin importar cuáles son sus conocimientos y, si quiere hacer carrera, tendrá además que ganar en la más resuelta estupidez si cabe al más tozudo de los especialistas" (2006: 25).

La determinación de Proust por ser escritor fue temprana, pero también lo fueron sus miedos y temores al fracaso y a la ausencia de no tener nada que decir.

\begin{abstract}
Puesto que yo quería ser escritor, ya era hora de ir pensando lo que iba a escribir. Pero en cuanto me hacía yo esta pregunta y trataba de encontrar un asunto en que cupiera una significación filosófica infinita, mi espíritu dejaba de funcionar, no veía más que un vacío delante de mi atención, me daba cuenta de que yo no tenía cualidad genial, o acaso que una enfermedad cerebral la impedía desarrollarse (2011-2018, I: 228-229).
\end{abstract}

El imperativo de responder a su vocación literaria se veía frustrado una y otra vez por una presunta incapacidad para la escritura:

¡Si al menos hubiera podido yo empezar a escribir! Pero cualesquiera que fuesen las condiciones en que abordase este proyecto (lo mismo, jay!, que el de no volver a tomar alcohol, acostarme temprano, dormir, estar bien), fuese 


\begin{abstract}
con arrebato, con método, con gusto, privándome de un paseo, aplazándolo y reservándolo como recompensa, aprovechando una hora de encontrarme bien, utilizando la inacción forzada de un día de enfermedad, lo que acababa siempre por resultar de mis esfuerzos era una página en blanco, virgen de toda escritura (2011-2018, III: 197).
\end{abstract}

La realización máxima de esta vocación es la composición de esta novela, que él mismo compara con la construcción compleja de una catedral gótica. Walter Benjamin, que había traducido a Proust al alemán, en un artículo que escribe en 1929 titulado "Para una imagen de Proust", cuenta una anécdota de Proust con su editor Gallimard. En el proceso de corrección de pruebas, Proust siempre las devolvía una y otra vez, no por encontrar errores tipográficos, sino porque rellenaba los márgenes de texto nuevo; a medida que leía todo de nuevo, las leyes del recuerdo seguían su curso.

\title{
2. El tema de la novela de Proust
}

Cuando nos enfrentamos a analizar una novela y a tratar de captar su sentido, lo primero que hacemos es preguntarnos cuál es su tema; ¿cuál es el tema de Proust? Esta ha sido una cuestión muy debatida entre los estudiosos del novelista, como Walter Benjamin, Harold Bloom, Ernst Robert Curtius, Guilles Deleuze, o Samuel Beckett. Como mera aficionada a la literatura me he tomado la libertad y la osadía de dar una respuesta que se anuncia en el título del artículo. Responder a esta cuestión es vital para entender por qué Ortega salvó a Proust y lo calificó de "inventor".

A primera vista, parece que el tema es el tiempo, como el título de la obra bien indica: la búsqueda del tiempo que ya pasó. Sin embargo, Borges escribía en su cuento El jardín de los senderos que se bifurcan que el verdadero tema de una obra nunca se menciona. A mi parecer, creo que este es el caso de Proust. Para Deleuze tampoco se trataba de una búsqueda del tiempo, sino más bien de la búsqueda de la verdad. Esta afirmación está estrechamente vinculada con la idea de Curtius de que el tema de Proust era el problema del conocimiento.

Otras interpretaciones, como la de H. E. Craig, sostienen que el tema de su novela fue la historia de su vocación literaria (1986: 453). El mismo Proust lo anunciaba en El tiempo recobrado: "la obra de arte era el único medio de recobrar el Tiempo perdido. Y comprendí que todos esos materiales de la obra literaria eran mi vida pasada [...] toda mi vida habría podido y no hubiera podido resumirse en este título: Una vocación" (2011-2018, VII: 274-275). Harold Bloom, en una lectura mucho más arriesgada, sostenía que el tema eran los celos sexuales por parte de las figuras masculinas. 
Sin embargo, todos estos posibles temas en el fondo son uno y tratan de apresar lo mismo con diferentes conceptos. El tema de Proust es el recuerdo, una cuestión que nunca se menciona. Sea dicho de paso que el material de ese recuerdo es su propia vida. Un recuerdo que se vierte en la forma del amor y de su deformación, los celos. El recuerdo permite atrapar o captar el tiempo, si bien, tan solo trazos de un determinado tiempo. Comprender cómo funcionan los recuerdos y cómo se gestan en la memoria es una cuestión que compete tratar a la teoría del conocimiento. Retener el recuerdo en la memoria y darle forma en el papel tiene una pretensión de totalidad y por tanto de alcanzar la verdad, la verdad del tiempo vivido. Es una remembranza de la experiencia vivida.

Paul Ricoeur, en su libro La memoria, la bistoria y el olvido (2000), empezaba planteándose dos preguntas para dar cuenta de una fenomenología de la memoria: la primera, ¿de qué hay recuerdo?; la segunda, ¿de quién es la memoria? (2003: 19). Y confesaba que ante estas dos preguntas se decantaba por plantear primero el "de qué" antes del "de quién", porque el "de qué" exponía una fenomenología del recuerdo consistente en su conservación y rememoración y el "de quién" derivaba en una reflexión psicológica de la experiencia mnemónica del sujeto. Entre ambas preguntas estaría la pregunta del "cómo" se recuerda, que alude a la reminiscencia o anamnesis.

La inevitabilidad del paso del tiempo se vertebra por medio de tres actos: la memoria, el recuerdo y el olvido. La literatura nos ofrece el marco idóneo donde contemplar la temporalidad, pues la memoria en la literatura se manifiesta tanto bajo la forma del recuerdo como del olvido (Marco Vega 2017: 62). El intento humano de recobrar el tiempo consiste en un ejercicio de memoria que lucha por no olvidar los recuerdos. Los personajes de Proust son víctimas de una condición y circunstancia predominante de la que no pueden escapar: el tiempo. La costumbre es lo único que se opone al paso del tiempo en Proust. Por eso, el lector tiene la constante sensación de que la obra no avanza narrativamente, porque lo que ahí se cuenta no es más que el fruto de la costumbre a la que se somete la vida. A esta costumbre y cotidianeidad de la vida de cada hombre, Unamuno la llamó "intrahistoria" en En torno al casticismo (1902). Con este concepto Unamuno buscaba dar cuenta de lo auténtico del alma española. La intrahistoria sería la reconstrucción de la vida cotidiana del hombre, o dicho de otro modo "el paisaje y el hombre en sus quehaceres cotidianos, expresan el tiempo vivido, sentido día a día; es la intrahistoria de Unamuno" (Margenot 2009).

Ortega sostenía que como en las obras de Proust el agente es el ambiente y hay una gran minuciosidad en la descripción, el lector sufría de fatiga, en el 
sentido de que la novela no nos deja avanzar. Frente al ansia de acción y progreso que tiene el hombre, porque es un ser dinámico, tal y como apuntó el filósofo madrileño, Proust trabajó contra esta necesidad de movimiento presentando una novela que carecía de dramatismo y que dejaba al lector en una actitud puramente contemplativa. Los personajes de Proust no son dramáticos y por ello Ortega afirmaba que carecían de centro. Benjamin también señalaba, en el ensayo Para una imagen de Proust, que Ortega supo ver bien que los personajes de Proust tenían una existencia vegetativa (2007, II-I: 324).

Sin embargo, que sus personajes no sean dramáticos no significa que la vida misma no lo sea. El drama de la vida es el Tiempo. Ortega solía decir que la vida es prisa y urgencia. El ser humano está condenado a la finitud de su vida y por tanto a carecer de Tiempo. El tiempo se constituye pues como un límite de nuestro horizonte de posibilidades. Un límite que siempre nos es impuesto. Ortega sostenía que el único límite a nuestra libertad era la continuidad con nuestro pasado:

En esa ilimitación principal de sus posibilidades, propia de quien no tiene una naturaleza, sólo hay una línea fija, preestablecida y dada, que pueda orientarnos; sólo hay un límite: el pasado. Las experiencias de vida hechas estrechan el futuro del hombre. Si no sabemos lo que va a ser, sabemos lo que no va a ser. Se vive en vista del pasado (2004-2010, VI: 72-73).

El hombre, ante la fatalidad del paso del tiempo, siempre tratará de apresarlo o recobrarlo y ese es el intento de Proust. El límite que Proust quería sobrepasar y, en el peor de los casos, el límite al que se quería asomar como si de una frontera se tratase, era el límite temporal: "si me diese siquiera el tiempo suficiente para realizar mi obra, lo primero que haría sería describir en ella a los hombres ocupando un lugar sumamente grande (aunque para ello hubieran de parecer seres monstruosos), comparado con el muy restringido que se les asigna en el espacio, un lugar, por el contrario, prolongado sin límite en el Tiempo" (2011-2018, VII: 462).

\section{El drama de la vida: el paso del tiempo}

La finitud de la vida pone en alerta al hombre, por eso Proust, según Ortega, es un investigador del tiempo perdido. Su pretensión no es restaurar el pasado sino describir aquello que aparece en su memoria a fin de no perder el tiempo vivido. Proust describió con una maravillosa metáfora botánica el inevitable 
paso del tiempo, o, dicho de otro modo, la llegada inexorable de la vejez como una simiente que ya está presente en la juventud: "En la flor más fresca ya se pueden distinguir esos puntos imperceptibles que para un alma despierta dibujan lo que habrá de ser, por la desecación o fructificación de las carnes que hoy están en flor, la forma inmutable y ya predestinada de la simiente" (20112018, II: 609). Proust estaba en Balbec, en plena juventud, descubriendo a las bellas y jóvenes flores de las que se enamoraría y a la vez siendo consciente de que esas bellas simientes se secarían algún día y que el tiempo pasado no volvería.

Siguiendo a Christian Moraru, la escritura de los recuerdos ${ }^{3}$ libera al autor del orden temporal, transportándolo a una "extratemporalidad" o "intemporalidad" (1995: 176), donde el pasado se personifica por medio del rememorar. De hecho, esta présentification del pasado de la que habló Walter Benjamin, según Moraru,

Has brought about a 'state of ecstasy', the ultimate outcome of remembrance in Proust, that is, a flight from time by a paradoxical and thorough immersing in it. What we have here, I would argue, is the novel's poetics summarized by the novel itself. A narrative poetics, but also a poetics of ecstasy, since the narrator's stated goal is ultimately the "contemplation of the essence of things" (1995: 177) $)^{4}$.

El filósofo alemán Odo Marquard, que postuló una filosofía escéptica de la finitud humana, escribió que el ser humano carece de tiempo precisamente porque la vida humana es breve.

La vida humana es breve. Nuestro futuro más cierto es nuestra muerte. Nuestro pasado más inevitable es nuestro nacimiento. Esto es válido para todo ser humano, pues (por decirlo sobriamente y evitando todo énfasis existencialista) hasta ahora la mortalidad y la natalidad de

\footnotetext{
${ }^{3}$ Para un análisis más detallado y extenso sobre la memoria y el recuerdo ver MORARU, Christian, Memorious Discourse: Reprise and Representation in Potmodernism. Nueva Jersey: Fairleigh Dickinson University Press, 2005.

4 Traducción propia: "ha provocado un 'estado de éxtasis', el resultado final del recuerdo en Proust, esto es, una huida del tiempo por medio de una inmersión paradójica y minuciosa en él. Lo que tenemos aquí, me gustaría argumentar, es la poética de la novela resumida por la propia novela. Una narrativa poética, pero también una poética del éxtasis, ya que el objetivo declarado del narrador es, en última instancia, la 'contemplación de la esencia de las cosas"'.
} 


\begin{abstract}
los seres humanos alcanzan un promedio del cien. El tiempo de nuestra vida (el periodo que media entre el único nacimiento por el cual cada uno viene al mundo, y la única muerte que cada uno muere) es un tiempo finito. No es una sucesión homogénea e ilimitada de momentos presentes que se originan en un punto indeterminado y que continúan fluyendo hacia lo indeterminado: tiene más bien un plazo fijo. Si tuviéramos tanto tiempo como quisiéramos, podríamos despilfarrarlo a voluntad sin que ello supusiera perder el tiempo: siempre habría más. Pero precisamente sucede que no hay más. Nuestro tiempo es finito, tiene un plazo, es escaso. El más escaso de nuestros escasos recursos es el tiempo de nuestra vida (2012: 13).
\end{abstract}

Esta brevedad nos obliga a vivir rápida y lentamente a la vez, porque esta breve vida solo la vivimos una vez. Para Marquard, la carencia de tiempo de los hombres finitos se compensaba con la pluralización de la vida, o, dicho de otro modo, con la comunicación con los otros. El relato literario se fundamenta sobre la premisa de que escritor y lector se embarcaran en un diálogo.

Donde mejor se puede vislumbrar el paso del tiempo, la lentitud y rapidez del mismo, es en el amor y en los celos — que son su deformación-, porque el amor es la pulsión más humana. ¿Es posible leer a Proust en la clave de "celos de amor", como sugiere Bloom? Se puede trazar una línea argumental a lo largo de los siete tomos de En busca del tiempo perdido cuyo núcleo es este tema. Desde el tomo I con el recelo que Swann siente hacia Odette cuando no logra localizarla, por ejemplo, pasando por el tomo II y III en Balbec, cuando Proust conoce a su amigo Saint-Loup y este siente un terrible sufrimiento a causa de su amada Raquel, y hasta el propio Proust, cuyos inquietudes amorosas van pasando de mujer a mujer, desde la pequeña Gilberta Swann, hasta Albertina, tan preocupado porque esta tenga deseos homosexuales que decide hacerla "prisionera" en su propia casa para poder controlarla y estar siempre con ella.

Proust sostenía que el amor nunca podía ser eterno debido al constante cambio y mutabilidad de los recuerdos. Dado que la vida es perpetua renovación, los recuerdos no permanecen inalterables y, por tanto, no se asemejan a lo que creíamos recordar. Chesterton sostenía en uno de sus relatos que el amor "es cosa de grandes momentos; y se alimenta del recuerdo de momentos" (2005: 59). El amor necesita de la rememoración de los momentos e instantes con el amado, pero esos recuerdos mutan y en ese cambio se van difuminando, se van haciendo menos claros y precisos y es entonces cuando afloran los celos, cuando el recuerdo no es nítido y tememos que el amado ya no nos corresponda. 
Del título que Ortega puso a su ensayo sobre Proust, "Tiempo, distancia y forma en el arte de Proust", se pueden ver tres ideas que resumían lo que el lector podía esperar de Proust: el tiempo es el recuerdo; la distancia tiene que ver con la distancia existente entre el narrador y las cosas descritas; y la forma apunta a la descripción de las cosas mismas. Para Ortega, Proust había reinventado el concepto de Tiempo, debido a que su actitud hacia el recuerdo modificaba la distancia y la forma. Por el contrario, Curtius sostuvo que el tiempo, al igual que el espacio, eran dos modos de vertebrar el recuerdo. El autor de la Recherche nos enseña que hay otra forma de acceder al pasado diferente de la rememoración: "la 'mémoire involontaire', casi siempre fruto del azar y capaz de desvelar los verdaderos recuerdos" (Marco Vega 2017: 192), nos ofrece esta puerta de entrada a lo que ya fue. En Proust, hay una contemplación del recuerdo que surge a través de la memoria involuntaria, pero no hay acción sobre el recuerdo.

Para entender el tipo de recuerdo que se gesta en la obra de Proust es imperativo diferenciar entre memoria voluntaria y memoria involuntaria o espontánea. Definiré la primera a través de la negación de la segunda. La memoria involuntaria consiste en evocar los recuerdos del pasado sin esfuerzo alguno. Es una memoria que brota por medio de la sensación y que está vinculada a la experiencia sensible. Dado que es espontánea también es impredecible y se da involuntariamente. Los recuerdos van apareciendo según el estímulo recibido del exterior y esos recuerdos no siguen una concepción del tiempo lineal (el mejor ejemplo para percibir esto y que citaré a continuación es el famoso pasaje de la magdalena). En la memoria involuntaria aparecen los recuerdos que están más allá de la voluntad. Precisamente la marca de autenticidad de estos recuerdos consiste, afirma Moraru,

in their involuntary resurfacing in the narrator's consciousness. Revisiting previously narrated event, the narrator does not initiate a purposeful search for the 'trueness of the past', but an unexpected confrontation with previous experiences, with fragments of contingent time (1995: 178) .

\footnotetext{
5 Traducción propia: "en su involuntario resurgimiento en la conciencia del narrador. Revisando un evento narrado previamente, el narrador no inicia una búsqueda intencionada de 'la verdad del pasado', sino una confrontación inesperada con experiencia previas, con fragmentos del tiempo contingente".
} 
Deleuze cargó las tintas contra esto y afirmó que la obra de Proust en modo alguno era una exposición de la memoria involuntaria, sino la narración de un aprendizaje (1995: 12).

El propósito de Proust, según Ortega, no era restaurar el pasado, "no quiere, valiéndose de sus recuerdos como de un material, reconstruir aquellas realidades antiguas, sino, al contrario, quiere, usando de todos los medios imaginables —observaciones de lo presente, análisis reflexivos, teorizaciones psicológicas-, llegar a reconstruir literariamente sus recuerdos" (2011-2018, II: 792).

\section{Volver al pasado por medio del recuerdo}

$\mathrm{Si}$, como he dicho, el tema de Proust es la reconstrucción o contemplación del recuerdo, veamos cómo se articula ese recuerdo en la memoria involuntaria. Pero antes, cabe hacer ejercicio etimológico:

El yo pasado, lo que ayer sentimos y pensamos vivo perdura en una existencia subterránea del espíritu. Basta con que nos desentendamos de la urgente actualidad para que ascienda a flor de alma todo ese pasado nuestro y se ponga de nuevo a resonar. Con una palabra de bellos contornos etimológicos decimos que lo recordamos esto es, que lo volvemos a pasar por el estuario de nuestro corazón. Dante diría per il lago del cor. Recordar es volver la vista al yo pretérito y hallarlo aún vivo y vibrátil como un dardo que sigue en el aire su carrera cuando el brazo que lo lanzó ya descansa (2004-2010, II: 295).

En este pasaje, Ortega sostiene que el recuerdo consiste en hallar el pasado todavía vivo en nuestro corazón. Etimológicamente, recordar proviene del latín recordare (re-: nuevo; cordere: cor, cordis) y significa pasar de nuevo por el corazón. $\mathrm{O}$, dicho de otro modo, recordar no es sólo lo que está en la memoria, sino lo que se queda en el corazón.

De esta manera funciona el recuerdo en Proust, por eso, el célebre pasaje de la magdalena le permite volver a revivir todo lo que estaba dormido en su corazón. La memoria del pasado viene con la magdalena que estimula el recuerdo de la experiencia vivida. Es en el estímulo sensorial al probar el gusto de la magdalena mojada en té cuando empiezan a reconstruirse los primeros recuerdos del pasado de manera totalmente involuntaria. Con este pasaje, de pronto el lector se encuentra sumergido en un Tiempo remoto a cuya 
ESMERALDA BALAgUER GARCÍA

representación solo asistirá en la medida en que las sensaciones del autor reactiven la historia de su vida pasada.

Y de pronto el recuerdo surge. Ese sabor es el que tenía el pedazo de magdalena que mi tía Leoncia me ofrecía, después de mojado en su infusión de té o de tila, los domingos por la mañana en Combray (porque los domingos yo no salía hasta la hora de misa) cuando iba a darle los buenos días a su cuarto. Ver la magdalena no me había recordado nada, antes de que la probara; quizá porque, como había visto muchas, sin comerlas, en las pastelerías, su imagen se había separado de aquellos días de Combray para enlazarse a otros más recientes; iquizá porque de esos recuerdos por tanto tiempo abandonados fuera de la memoria, no sobreviven nada y todo se va disgregando. [...] Pero cuando ya nada subsiste de un pasado antiguo, cuando han muerto los seres y se han derrumbado las cosas, solos, más frágiles, más vivos, más inmateriales, más persistentes y más fieles que nunca, el olor y el sabor perduran mucho más, y recuerdan, y aguardan, y esperan sobre las ruinas de todo, y soportan sin doblegarse en su impalpable gotita el edificio enorme del recuerdo.

En cuanto conocí el sabor del pedazo de magdalena mojado en tila que mi tía me daba [...], la vieja casa gris con fachada a la calle, donde estaba su cuarto, vino como una decoración de teatro a ajustarse al pabelloncito del jardín que detrás de la fábrica principal se había construido para mis padres, y en donde estaba ese truncado lienzo de casa que yo únicamente recordaba hasta entonces; y con la casa vino el pueblo, desde la hora matinal hasta la vespertina y en todo tiempo, la plaza, adonde me mandaban antes de almorzar, y las calles por donde iba a hacer recados, y los caminos que seguíamos cuando hacia buen tiempo (2011-2018, I: 70).

El tema de Proust es el recuerdo de las cosas, no las cosas que se recuerdan y en este sentido, para Ortega, Proust fue investigador de una facultad humana: la memoria. El mecanismo de la memoria tiene sus reglas. El acceso a la memoria siempre es parcial, porque el olvido ya ha operado en aquello que somos capaces de recordar. En el recuerdo hay un fuerte componente de perspectiva. Cada vez que volvemos la vista atrás hacia nuestras experiencias, el 
recuerdo de estas se alcanza con diferente proximidad. La imagen del pasado no se reconstruye todas las veces desde la misma perspectiva.

Según Ortega, hay en Proust una radical transformación de la perspectiva literaria, porque la relación con cada cosa o cada experiencia nos impone una determinada distancia desde la que obtenemos su mejor apariencia. Proust quería adentrarse en la intimidad humana. "A Proust no le interesan las manos ni, en general, las cosas corporales tanto como la fauna y flora íntimas. Rectifica nuestra distancia ante los sentimientos humanos y rompe con la tradición de describirlos monumentalmente" (2004-2010, II: 793).

Para Benjamin, Proust había inventado un nuevo género porque describía la vida tal y como la recuerda quien la ha experimentado. La obra de Proust era "la obra de toda una vida" y reunía "poesía, labor de memorialista y un comentario" (2007: 239). El papel principal está desempeñado por el tejido de los recuerdos. Benjamin también señalaba en su ensayo que el acto de memoria involuntaria o espontánea de Proust estaba más cerca del olvidar que del recordar, porque cada nuevo día pone en libertad el olvido de aquellos recuerdos que nuestra memoria no ha sido capaz de apresar. Benjamin definía los procesos de rememoración como una présentification o Vergegenwärtigung. Sostiene Marco Vega en su tesis doctoral que la Recherche es un ejemplo paradigmático de présentification del pasado debido al experimento de anamnesis que realizó Proust (2017: 37).

\section{La necesidad del olvido}

El tiempo trae progresivamente el olvido, escribía Proust. Es necesario que el olvido opere en nuestra memoria si queremos seguir pensando. Porque pensar es generalizar, olvidar diferencias y no recordar el mínimo detalle de todo lo que hemos visto o aprendido. Es necesario que no todo sea apresado en la memoria. Sin embargo, olvidar completamente todo (como les sucede a aquellos que padecen alzhéimer, por ejemplo) es un drama. Como Ortega solía decir "el hombre no tiene naturaleza, sino que tiene... historia" (2004-2010, VI: 73). Esto es una exageración, no es que el hombre no sea natural, sino que su principal rasgo es que es histórico, el hombre vive desde su pasado, necesita contar con él precisamente porque le es inevitable. Si el hombre olvida todo y es incapaz de recordar su pasado, será imposible que proyecte una imagen futura de sí mismo para su realización. En la segunda consideración intempestiva, titulada De la utilidad y los inconvenientes de la historia para la vida (1874), Nietzsche afirmaba que el olvido era el fármaco que necesitaba el hombre para luchar contra la enfermedad histórica: "es posible vivir, y aún vivir feliz, casi sin recordar, como lo muestra el animal; pero es totalmente imposible 
vivir sin olvidar" (2018: 38). En toda acción debe haber olvido, proseguía Nietzsche, de lo contrario, un hombre que fuera incapaz de olvidar estaría condenado a percibir el devenir y ya no creería ni en su propio ser. Esta idea la ilustra maravillosamente Borges en su célebre cuento Funes el memorioso, en el cual nos narra la historia de Ireneo Funes, un hombre cuya condena fue precisamente la contraria al ejercicio involuntario del olvido, o, dicho de otro modo, su gran drama fue el de recordar el más mínimo detalle de todo lo que experimentaba.

Para Benjamin, el estudio del tiempo que realizó Proust nos abría un nuevo género de eternidad, que estaba confinado por el correr del tiempo y limitado por el espacio, el cual se expresa interiormente por medio del recuerdo y exteriormente por medio del envejecimiento. El tiempo moldea en los hombres el carácter de la madurez. El acto de recordar el pasado por medio de la memoria involuntaria es la fuerza rejuvenecedora que encuentra Proust en la amargura de la vejez y del saberse cercano a la muerte.

Mientras que lo pasado se refleja en un instante recién nacido, un golpe doloroso arrebata incesantemente toda la juventud reconquistada [...] Proust ha terminado de preparar ese monstruo que le permite, en un instante, hacer envejecer a todo el mundo en una sola vida humana. Pero inclusive esa concentración, en la cual lo que tiene que marchitarse y apagarse se transforma con la velocidad del rayo, es un rejuvenecimiento (2007: 248).

Por eso Benjamin consideraba que el objetivo de la obra de Proust era llenar la vida con la presencia del espíritu, precisamente porque el hombre no dispone del tiempo suficiente para vivir todos los dramas de la existencia y esto nos envejece. La literatura y en particular, En busca del tiempo perdido, es un ejercicio de compensación vital, siguiendo la estela de Marquard. Frente al inevitable olvido de nuestras pocas experiencias y frente a la finitud de la vida, la literatura nos permite vivir otros mundos posibles, ensancha nuestra experiencia del mundo y genera un tipo de recuerdo — si bien ficcional— que nos acerca más a la juventud que a la vejez.

\section{Memoria y trascendencia}

¿Cuál fue la pretensión de Proust con su obra? El escritor quiso alcanzar la inmortalidad de sus recuerdos, que estos perduraran y trascendieran el espacio y el tiempo por medio del acto de la escritura. Sostiene Moraru que la escritura es una afirmación de la libertad en tanto que rompe con las fronteras temporales: 
"It aims at displacing the slavish condition of being human — a being in time, confined to temporal limits — in and through the act of artistic creation" (1995: 186) ${ }^{6}$. A nuestro escritor no le interesaba, en cambio, la inmortalidad de su ser, como si pretendía alcanzar con sus novelas Unamuno. Él perseguía no solo la inmortalidad de su alma, sino también la de su cuerpo. Para Unamuno, la literatura era expresión de la muerte, pero quien podía leer una novela podía vivirla y revivirla y mientras este mecanismo funcionara, el autor seguiría vivo, porque toda novela para Unamuno era autobiográfica.

En cuanto un pensamiento nuestro queda fijado por la escritura, expresado, cristalizado, queda ya muerto y no es más nuestro que será un día bajo tierra nuestro esqueleto. La historia, lo único vivo, es el presente eterno, el momento huidero que se queda pasando, que pasa quedándose, y la literatura no es más que muerte. Muerte de que otros pueden tomar vida. Porque el que lee una novela puede vivirla, revivirla [...] Toda novela, toda obra de ficción, todo poema, cuando es vivo, es autobiográfico. Todo ser de ficción, todo personaje poético que crea un autor hace parte del autor mismo (Unamuno 2012: 66, 98).

Proust escribió su obra con vistas a la muerte, escribía Benjamin, porque sobre su vida ya planeaba la sombra del envejecer:
A mayor escala, la muerte viene a ser eso que Proust tenía presente de modo continuo, sobre todo mientras escribía, la brutal amenaza de la crisis de ahogo. Así estaba la muerte frente a Proust, pero lo estuvo durante mucho tiempo, bastante antes de que su enfermedad adquiriera al fin su forma crítica. Mas no como manía hipocondríaca, sino ya en tanto que réalité nowvelle, como aquella nueva realidad cuyo reflejo sobre las cosas y los hombres son ya los rasgos del envejecimiento (Benjamin 2007: 329-330).

En el Fedro, Platón nos habla del mito de la escritura por medio de Theuth y Thamus, rey de una gran ciudad del Alto Egipto. Allí vivía uno de los antiguos dioses del país, Theuth, que descubrió la geometría, la astronomía y las letras. Durante el reinado de Thamus, Theuth fue a verle para decirle que sus artes

${ }^{6}$ Traducción propia: "Su objetivo es desplazar la condición esclavizante del ser humano —un ser temporal, confinado a límites temporales- en y a través del acto de la creación artística". 
debían ser entregadas a los egipcios. Thamus quiso saber las ventajas que reportaban cada una de estas artes antes de emitir un juicio favorable o desfavorable sobre si debían ser accesibles a toda la población. Cuando Theuth le habló de la escritura, le hizo saber que esta aumentaba la memoria. Thamus le respondió que la escritura no ayudaba a la memoria sino más bien al olvido. La escritura es un reflejo del recuerdo, no de la memoria, porque no puede ejercitarla.

Pero una vez que hubo llegado a la escritura, dijo Theuth: "Este conocimiento, oh rey, hará más sabios a los egipcios y aumentará su memoria. Pues se ha inventado como un remedio de la sabiduría y la memoria”. Y aquél replicó: "Oh, Theuth, excelso inventor de artes, unos son capaces de dar el ser a los inventos del arte, y otros de discernir en qué medida son ventajosos o perjudiciales para quienes van a hacer uso de ellos. Y ahora tú, como padre que eres de las letras, dijiste por cariño a ellas el efecto contrario al que producen. Pues este invento dará origen en las almas de quienes lo aprendan al olvido, por descuido del cultivo de la memoria, ya que los hombres, por culpa de su confianza en la escritura, serán traídos al recuerdo desde fuera, por unos caracteres ajenos a ellos, no desde dentro, por su propio esfuerzo. Así que no es un remedio para la memoria, sino para suscitar el recuerdo lo que es tu invento. Apariencia de sabiduría y no sabiduría verdadera procuras a tus discípulos (Platón 2007: 274c).

En este punto cabe preguntarse si las palabras que quedan apresadas en el papel no son más que el reflejo de los pensamientos olvidados de quien los escribió o el último intento de apresar los pocos recuerdos que todavía quedan en su memoria.

Del mismo modo que si queremos hablar o decir algo tenemos que callar o silenciar muchas cosas para poder decir otras, al pretender recordar tenemos que olvidar otras tantas para que la memoria siga su curso. Esta idea está estrechamente vinculada con el concepto orteguiano de "Nueva filología". En "Apuntes para un comentario al banquete de Platón", Ortega sostenía que leer era una faena utópica, porque de nuestra lectura solo extraemos una porción de lo que se quiso decir y a su vez se revelan otras tantas cosas que el autor no tuvo intención de mencionar. $\mathrm{O}$, dicho de otro modo, el lenguaje entraña un discurso patente y otro latente. Esto se debía a los dos principios que caracterizan a la Nueva Filología: el primero, todo decir es deficiente (dice 
menos de lo que quiere); el segundo, todo decir es exuberante (da a entender más de lo que se propone). Por tanto, para entender lo que Proust quiso decir cuando escribió su novela, hay que ir más allá de su lectura, hay que saber más de por qué su autor tomó esa tarea como su quehacer o bandlung, porque el decir es un hacer de un hombre.

Sin embargo, Ortega escribió, siguiendo a Platón, precisamente siguiendo esta idea del Fedro, que el verdadero decir era el diálogo y que el libro era un decir fijado y petrificado, era una expresión paralítica o cadavérica, porque "el libro es para nosotros ausencia del autor y el decir escrito, fuga previa del que lo dice. Tenemos un decir sin actual dicente" (2004-2010, IX: 743). En esta medida, el problema que plantea la lectura de los libros es que muchos de los enigmas que se nos presentan permanecerán irresolutos.

Ante la cercanía de la muerte, Proust intentó recobrar el tiempo perdido por medio del arte. Su vida pasada, la que nos relata, fue el material idóneo para su obra literaria.

¿Consiguió Proust recobrar el tiempo perdido por medio de la escritura de sus recuerdos? Para Ortega, Proust sí logró edificar la ruina del pasado, porque había encontrado una nueva manera de ver, y por eso lo calificó de inventor. Este ver de Proust presenta sin duda una paradoja: la rememoración del tiempo pasado en el presente nos permite recuperar el pasado a costa de perder el presente, pagando el coste de salir fuera de la temporalidad actual.

\section{Referencias bibliográficas}

ADORNo, Theodor W., Gesammelte Schriften in zwanzig Bänden. 4: Minima Moralia. Reflexionen aus dem beschädigten Leben. Berlín: Suhrkamp Verlag, 2003. Traducción al español: Minima Moralia. Reflexiones desde la vida dañada, trad. de Joaquín Chamorro Mielke. Madrid: Akal, 2006.

BENJAMIN, Walter, Gesammelte Schriften. Band II-I: Frühe Arbeiten zur Bildungs- und Kulturkritik/Metaphysisch-geschichtsphilosophische Studien/Literarische und ästhetische Essays. Berlín: Suhrkamp Verlag, 1977. Traducción al español: "Hacia la imagen de Proust”. En: Obras, trad. de Jorge Navarro Pérez. Madrid: Abada Editores, 2007, libro II, vol. I.

BLOOM, Harold (ed.), "Introduction”. En: Bloom's modern critical views. Marcel Proust, Chelsea House Publisher, Philadelphia, 2004, pp. 1-16.

Chesterton, G. K., "The crime of capitan Gahagan". En: The paradoxes of Mr. Pond. Los Ángeles: Indo-European Publishing, 2011. Traducción al español: "El crimen del capitán Gahagan". En: Las paradojas de Mr. Pond, trad. de Fernando Jadraque y María Trouillhet. En: Madrid, Valdemar, 2005. 
CRAIG, Herbert E., "Ideas de Ortega y Gasset sobre la novela proustiana". En: Bulletin Hispanique, 88, 3-4, 1986, pp. 445-456.

CuRTIUS, Ernst Robert, Marcel Proust. Berlín: Suhrkamp Verlag, 1952.

Deleuze, Gilles, Proust e les signes. París: Presses Universitaires de France, 2014. Traducción al español: Proust y los signos, trad. de Francisco Monge. Barcelona: Anagrama, 1995.

MARCo VegA, José Carlos, Narración, memoria e identidad en Jean-Christophe: el sueño europeo de Romain Rolland, Tesis Doctoral dirigida por M. ${ }^{a}$ Lourdes Carriedo López y Arno Gimber. Madrid: UCM, 2017.

MARQuard, Odo, Individuum und Gewaltenteilung. Philosophische Studien. Ditzingen: Reclam, 2004. Traducción al español: Individuo y división de poderes. Estudios filosóficos, trad. de José Luis López de Lizaga. Madrid: Trotta, 2012.

MORARU, Christian, "Time, Writing, and Ecstasy in Speak, Memory: Dramatizing the Proustian Project". En: Nabokov Studies, 2, 1995, pp. 173-190.

NiETZSCHE, Friedrich, "Vom Nutzen und Nachteil der Historie für das Leben”. En: Unzeitgemäße Betrachtungen. Berlín: Holzinger, 2016. Traducción al español: De la utilidad y los inconvenientes de la historia para la vida. Segunda consideración intempestiva, trad. de Joan B. Llinares. Madrid: Tecnos, 2018.

ORTEGA Y GASSET, José, “Tiempo, distancia y forma en el arte de Proust". En: Obras Completas. Madrid: Taurus/Fundación José Ortega y Gasset, 20042010, tomo II.

, "Azorín o primores de lo vulgar". En: Obras Completas. Madrid: Taurus/Fundación José Ortega y Gasset, 2004-2010, tomo II.

-, "Apuntes para un comentario al banquete de Platón". En: Obras Completas. Madrid: Taurus/Fundación José Ortega y Gasset, 2004-2010, tomo II.

—_, "Nota a 'Marcelo Proust' de Benjamín Crémieux". En: Obras Completas. Madrid: Taurus/Fundación José Ortega y Gasset, 2004-2010, tomo III.

_- "Ideas sobre la novela". En: Obras Completas. Madrid: Taurus/Fundación José Ortega y Gasset, 2004-2010, tomo III.

- "Historia como sistema". En: Obras Completas. Madrid: Taurus/Fundación José Ortega y Gasset, 2004-2010, tomo VI.

Platón, Fedro. Madrid: Alianza Editorial. Clásicos de Grecia y Roma, 2007.

PROust, Marcel, En busca del tiempo perdido, trad. de Pedro Salinas y Consuelo Berges. Madrid: Alianza, 7 vol., 2011-2018.

Ricoeur, Paul, La mémoire, l'histoire, l'oubli. París: Seuil, 2003. Traducción al español: La memoria, la historia, el olvido, trad. de Agustín Neira. Madrid: Trotta, 2003. 
La perspectiva del recuerdo: Proust desde Ortega

MARGENOT, Maricarmen R., "Intrahistoria en Unamuno e intratiempo en Machado". En: Espéculo. Revista de estudios literarios, 42, 2009. Disponible en línea en: www.ucm.es/info/especulo/numero42/intrahis.html. [Fecha de consulta: 11 de julio de 2019]. 